Article

\title{
Synthesis of Some Novel Pyrazolo[1,5-a]pyrimidine Derivatives and Their Application as Disperse Dyes
}

\author{
Alya M. Al-Etaibi ${ }^{1}{ }^{*}$, Nouria A. Al-Awadi ${ }^{2}$, Morsy A. El-Apasery ${ }^{2}$ and Maher R. Ibrahim ${ }^{2}$ \\ 1 Natural Science Department, College of Health Science, Public Authority for Applied Education \\ and Training, Kuwait \\ 2 Chemistry Department, Faculty of Science, Kuwait University, P.O. Box 5969, Safat 13060, \\ Kuwait
}

* Author to whom correspondence should be addressed; E-Mail: alya.aletaibi@yahoo.com.

Received: 1 June 2011; in revised form: 9 June 2011 / Accepted: 15 June 2011 /

Published: 22 June 2011

\begin{abstract}
A series of novel monoazo-disperse dyes containing pyrazolo[1,5-a]pyrimidine structures were synthesized starting with the coupling reaction between ethyl cyanoacetate and 4-hydroxybenzenediazonium chloride, followed by treatment of the resulting hydrazone product with hydrazine hydrate. The pyrazolohydrazone 6 is then treated with either 2,4-pentandione and enaminonitrile or aryl-substituted enaminoketones to give the target pyrazolo[1,5-a]pyrimidine dyes 7 and 15a-d. Structural assignments to the dyes were made using NMR spectroscopic methods. A new high temperature method, using microwave heating, was employed to apply these dyes to polyester fibers. Most of the dyed fabrics tested displayed moderate light fastness and excellent washing fastness properties.
\end{abstract}

Keywords: enaminone; pyrazolohydrazone; microwave irradiation; disperse dyes; HMBC 2-D, 2,4-pentandione; enaminonitrile

\section{Introduction}

Pyrazole derivatives are important intermediates in organic synthesis and possess a range of interesting biological and antimicrobial properties [1-8]. Their fused pyrimidine derivatives are used as dyes [9-14]. In the current study, we prepared new azopyrazolopyrimidine dyes, starting with 
3-amino-4-(4-hydroxyphenyl)azo-1H-2-pyrazoline-5-ones and 3-(4-hydroxyphenylazo-1H-2-pyrazoline-5ones, and applied them to polyester fibers as disperse dyes by using a new high temperature microwave heating method. Microwave irradiation leads to a large increase in dye uptake and dyeing rate, along with a performance of dye leveling and color homogeneity than can be achieved by using conductive heating [15-17].

\section{Results and Discussion}

\subsection{Synthesis and Characteristics}

Ethyl 2-arylhydrazonocyanoacetate 4 was formed by addition under mild conditions of ethyl cyanoacetate (1) to 4-hydroxybenzenediazonium chloride (2) that readily affords the corresponding hydrazone 3. The existence of this substance in the quininoid form 5 was ruled out based on the results of NOE difference experiments, which showed that irradiation of the two NH signals at 12.1 and $13.0 \mathrm{ppm}$ caused an enhancement of the intensities of the aryl proton resonances at 6.3 and $6.8 \mathrm{ppm}$, while irradiation of the two $\mathrm{OH}$ signals at 9.68 and $9.57 \mathrm{ppm}$ also resulted in an increase in the intensities of the aryl proton peak at $6.8 \mathrm{ppm}$. Moreover, the ${ }^{13} \mathrm{C}-\mathrm{NMR}$ spectrum of 3 shows only two sets of two $\mathrm{sp}^{3}$ carbon signals at 61.7 and 61.2 , and 14.20 and 14.0 corresponding to the ethyl group. In addition, the data demonstrate that the hydrazone product exists as a 1:2 equilibrium mixture of syn- (3) and anti-forms (4) (Scheme 1). The major isomer is assumed to have the syn-stereochemistry 4 based on the expectation that its $\mathrm{NH}$ proton would be deshielded in the ${ }^{1} \mathrm{H}-\mathrm{NMR}$ spectrum as a result of potential hydrogen bonding with the carbonyl ester moiety (cf. Scheme 1).

Scheme 1. Preparation of hydroxyphenylhydrazonopyrazolone 6.

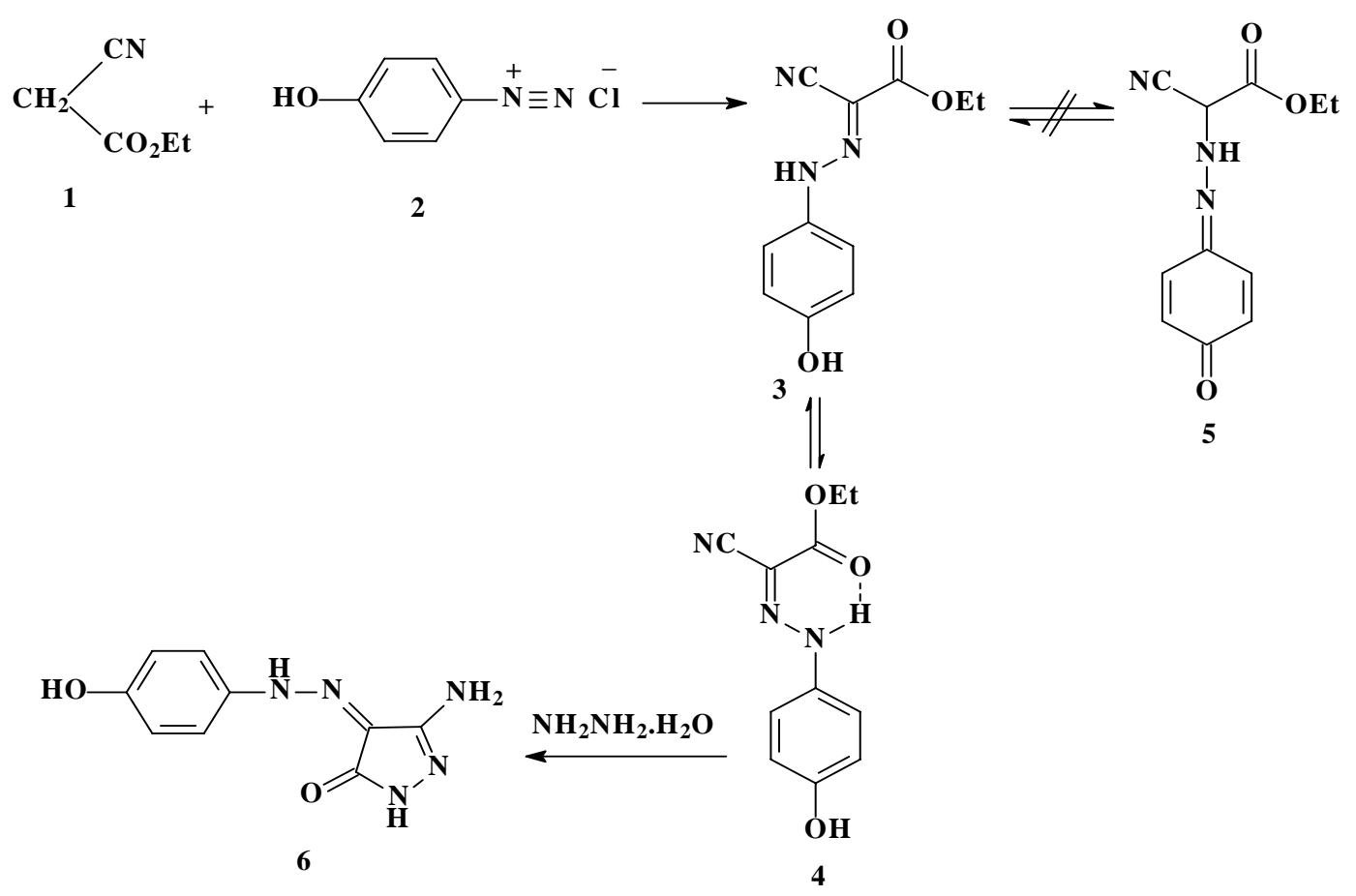

Brecknell et al. [18] was able to isolate and characterize both isomers. The predominance of the anti-form of 2-phenylhydrazonoacetate was attributed to stereoelectronic effects. Recently Al-Awadi et al. 
have shown that in similar systems stereoelectronic effects are more important than hydrogen bonding in governing syn-anti ratios [19].

Hydrazone 3 undergoes a smooth reaction with hydrazine hydrate to yield 4-(4-hydroxyphenylhydrazonopyrazolone 6. The structure and the chemistry of such compounds have received considerable attention [20-22]. We have observed that 6 readily condenses with acetylacetone to yield the pyrazolo[1,5-a]pyrimidine 7 , which has the potential of existing in tautomeric form $\mathbf{8}$. However, the $2 \mathrm{D}{ }^{1} \mathrm{H}-\mathrm{NMR}$ analysis results indicate that it exists in only one form having the nonquinoidal structure 7 (cf. Scheme 2).

Scheme 2. Synthesis of 3-(4-hydroxyphenylazo)-5,7-dimethylpyrazolo[1,5-a]pyrimidin-2one (8) and 7-amino-3-(4-hydroxyphenylazo)-pyrazolo[1,5-a]pyrimidin-2-one (12).<smiles>Nc1ccn2[nH]c(=O)c(NN=C3C=CC(=O)C=C3)c2n1</smiles>

13<smiles>C=C=C</smiles>

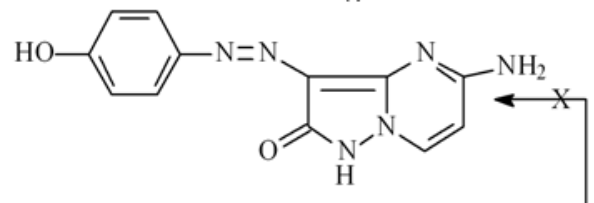

11

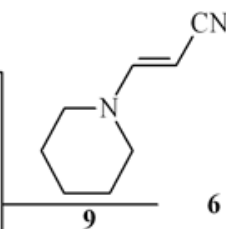<smiles>CC(=O)CC(C)=O</smiles><smiles></smiles>
7 1 10<smiles>C=C=C1NN2C(N)=CC=NC2=C1NN=C1C=CC(=O)C=C1</smiles><smiles>Cc1cc(C)n2[nH]c(=O)c(NN=C3C=CC(=O)C=C3)c2n1</smiles>

8

12

The important features of the HMBC 2-D ${ }^{1} \mathrm{H}$, and ${ }^{13} \mathrm{C}$ signals are shown in Figure $1 . \mathrm{H}^{6}$ at $7.06 \mathrm{ppm}$ correlates with $\mathrm{C}^{5}$ and $\mathrm{C}^{7}$ at 161.2 and $146.4 \mathrm{ppm} ; \mathrm{H}^{13}$ at $7.63 \mathrm{ppm}$ correlates with $\mathrm{C}^{12}$ and $\mathrm{C}^{15}$ at 141.5 and $158.4 \mathrm{ppm} ; \mathrm{H}^{14}$ at $6.88 \mathrm{ppm}$ correlates with $\mathrm{C}^{13}$ and $\mathrm{C}^{15}$ at 121.6 and $158.4 \mathrm{ppm} ; \mathrm{H}^{16}$ at $2.51 \mathrm{ppm}$ correlates with $\mathrm{C}^{5}$ and $\mathrm{C}^{7}$ at 161.2 and $146.4 \mathrm{ppm}$; and $\mathrm{H}^{17}$ at $2.58 \mathrm{ppm}$ correlates with $\mathrm{C}^{6}$ and $\mathrm{C}^{7}$ at 111.9 and 146.4 ppm.

${ }^{1} \mathrm{H}^{-15} \mathrm{~N}$ HMBC experiments add further support to the assignment of structure 7 , such as the chemical shifts observed for $\mathrm{N}^{7 \mathrm{a}}$ at $210 \mathrm{ppm}, \mathrm{N}^{4}$ at $260 \mathrm{ppm}$ and $\mathrm{N}^{12 \mathrm{a}}$ at $370 \mathrm{ppm}$, the cross peak correlations for coupling of $\mathrm{H}^{6}$ at $7.06 \mathrm{ppm}$ is also observed with $\mathrm{N}^{7 \mathrm{a}}$ at $210 \mathrm{ppm}\left({ }^{3} J\right)\left(\mathrm{H}^{6}, \mathrm{~N}^{7 \mathrm{a}}\right)$, and $\mathrm{N}^{4}$ 
at $260 \mathrm{ppm}\left({ }^{3} J\right)\left(\mathrm{H}^{6}, \mathrm{~N}^{4}\right)$. Interestingly, coupling of $\mathrm{H}^{16}$ at $2.51 \mathrm{ppm}$ with only $\mathrm{N}^{4}$ at $260 \mathrm{ppm}\left({ }^{3} J\right)$ $\left(\mathrm{H}^{16}, \mathrm{~N}^{4}\right)$ is observed, coupling of $\mathrm{H}^{17}$ at $2.58 \mathrm{ppm}$ takes place only with $\mathrm{N}^{7 \mathrm{a}}$ at $210 \mathrm{ppm}\left({ }^{3} J\right)\left(\mathrm{H}^{17}, \mathrm{~N}^{7 \mathrm{a}}\right)$ (Figure 1).

Figure 1. ${ }^{1} \mathrm{H}$ - and ${ }^{13} \mathrm{C}-\mathrm{NMR}$ spectroscopy assignments of compound 7.
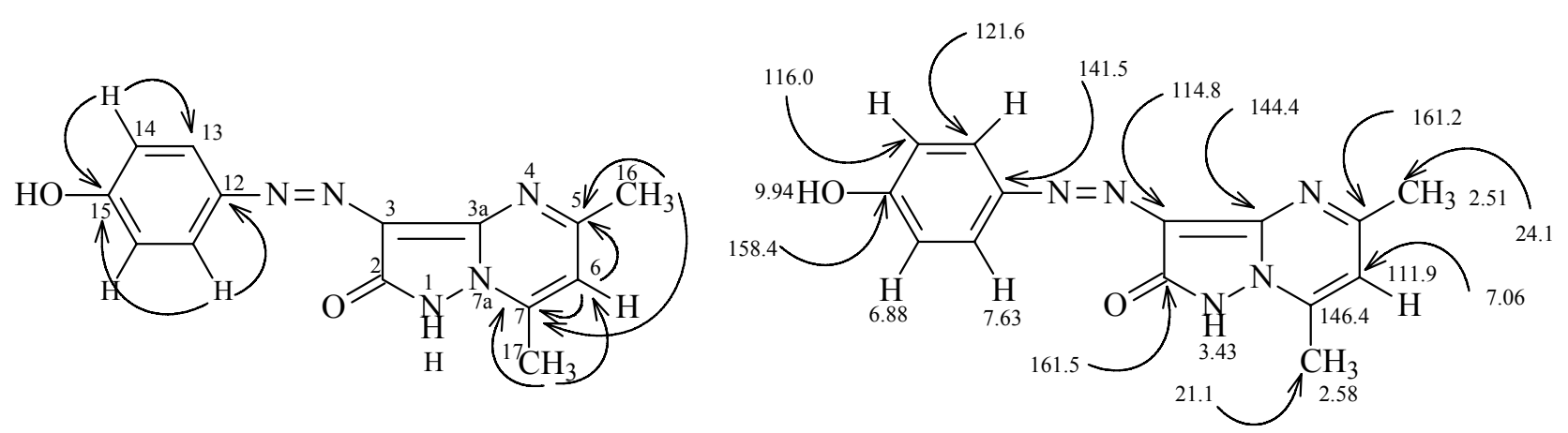

Hydroxyphenylhydrazonopyrazolone 6 also reacts with 2-piperidinylacrylonitrile (9) to yield a product for which structures 10-13 are possible based on the absence of an amino-proton resonance in their ${ }^{1} \mathrm{H}-\mathrm{NMR}$ spectra and a cyano band in the IR spectrum. The assignment of structure $\mathbf{1 0}$ was made by H-C correlations in the HMBC 2-D experiments (Figure 2).

Figure 2. ${ }^{1} \mathrm{H}$ and ${ }^{13} \mathrm{C}$ NMR spectroscopy assignments of compound $\mathbf{1 0}$.
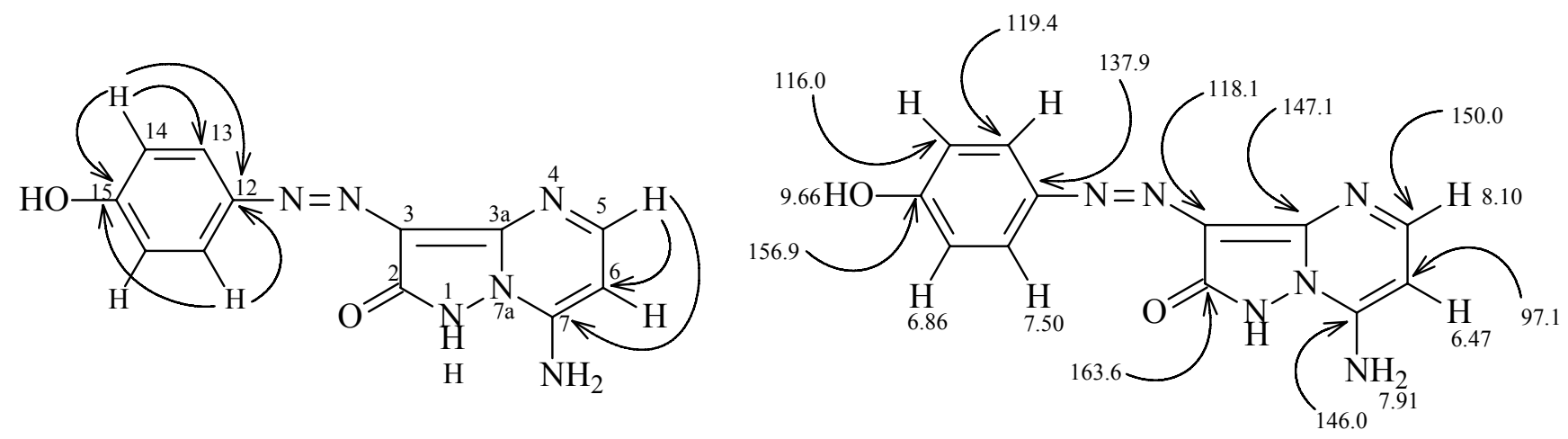

The correlations of $\mathrm{H}^{5}$ at $8.10 \mathrm{ppm}$ with $\mathrm{C}^{6}$ and $\mathrm{C}^{7}$ at 97.1 and $146.0 \mathrm{ppm}, \mathrm{H}^{13}$ at $7.51 \mathrm{ppm}$ with $\mathrm{C}^{12}$ and $\mathrm{C}^{15}$ at 137.9 and $156.9 \mathrm{ppm}$, and $\mathrm{H}^{14}$ at 6.90 with $\mathrm{C}^{12}, \mathrm{C}^{13}$ and $\mathrm{C}^{15}$ at $137.9,119.4$ and $156.9 \mathrm{ppm}$ were observed, further structural information came from the results of ${ }^{1} \mathrm{H}^{-15} \mathrm{~N}$ HMBC experiments, the chemical shifts for $\mathrm{N}^{7 \mathrm{a}}$ and $\mathrm{N}^{4}$ are 198.7 and $234.2 \mathrm{ppm}$, respectively, cross peak correlations for coupling of the shielded proton $\mathrm{H}^{6}$ at $6.47 \mathrm{ppm}$ takes place with $\mathrm{N}^{7 \mathrm{a}}$ at $198.7 \mathrm{ppm}\left({ }^{3} \mathrm{~J}\right)(\mathrm{H}-6, \mathrm{~N}-7 \mathrm{a})$ and $\mathrm{N}^{4}$ at $234.2 \mathrm{ppm}\left({ }^{3} \mathrm{~J}\right)(\mathrm{H}-6, \mathrm{~N}-4)$, coupling of the deshielded proton $\mathrm{H}^{5}$ at $8.10 \mathrm{ppm}$ with only $\mathrm{N}^{4}$ at 234.2 ppm $\left({ }^{3} J\right)(\mathrm{H}-5, \mathrm{~N}-4)$ is also observed.

Compound 6 reacts with enaminones 14a-d to yield the corresponding pyrazolo[1,5-a]pyrimidines 15a-d (cf. Scheme 3) whose identities were established by using 2D NMR experiments (Figure 3). 
Scheme 3. Synthesis of pyrazolo[1,5-a]pyrimidinone derivatives.

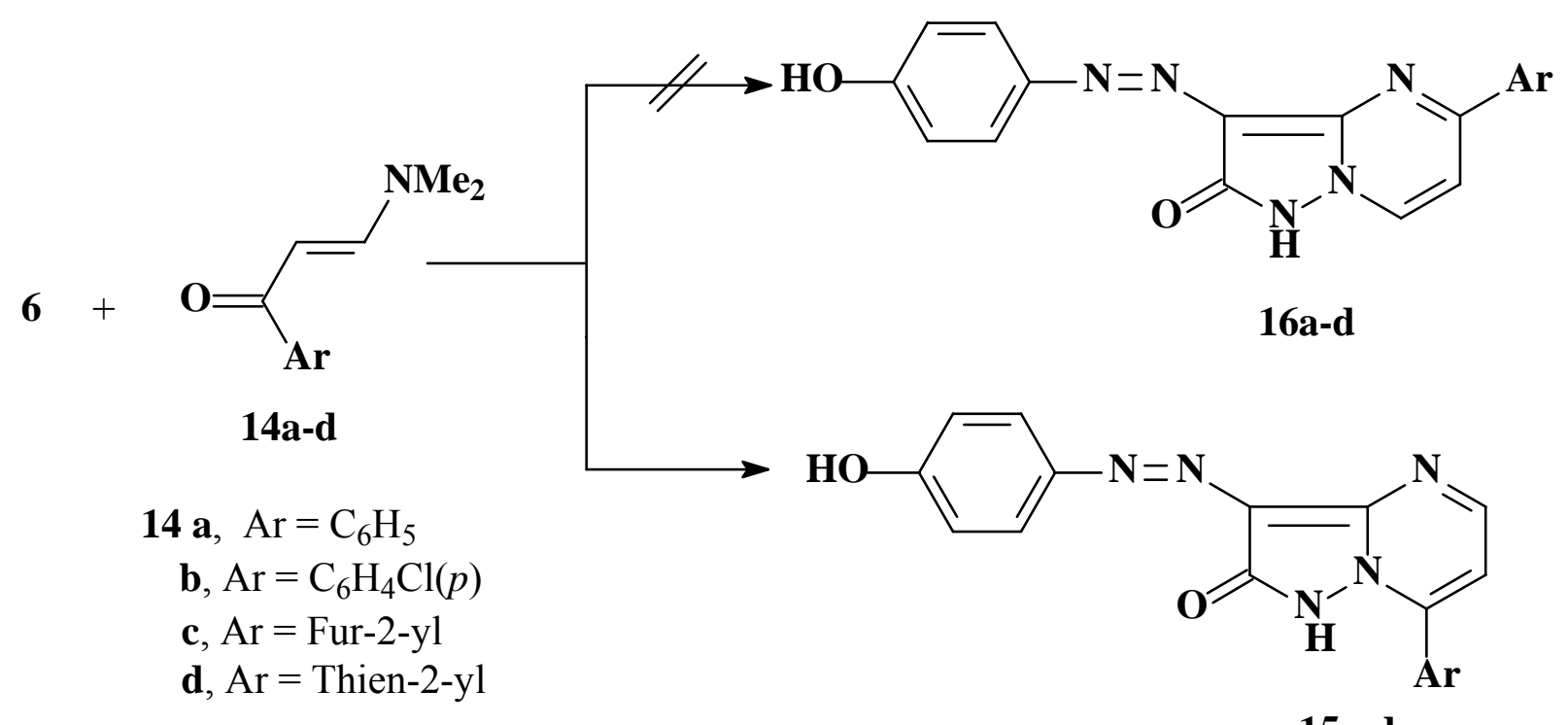

15a-d

${ }^{1} \mathrm{H}$ and ${ }^{13} \mathrm{C}$ signal assignments and HMBC 2-D derived $\mathrm{H}-\mathrm{C}$ correlations for 15a. The important features of the $\mathrm{HMBC}$ correlations are the $\mathrm{H}^{5}$ at $8.7 \mathrm{ppm}$ with $\mathrm{C}^{7}$ at $145.0 \mathrm{ppm}, \mathrm{H}^{6}$ at $7.38 \mathrm{ppm}$ with $\mathrm{C}^{7}$ and $\mathrm{C}^{8}$ at 145.0 and $130.1 \mathrm{ppm}, \mathrm{H}^{9}$ at $8.07 \mathrm{ppm}$ with $\mathrm{C}^{11}$ at $131.3 \mathrm{ppm}, \mathrm{H}^{10}$ at $7.64 \mathrm{ppm}$ with $\mathrm{C}^{8}$ at $130.1 \mathrm{pm}, \mathrm{H}^{11}$ at $7.64 \mathrm{ppm}$ with $\mathrm{C}^{9}$ at $129.7 \mathrm{ppm}, \mathrm{H}^{13}$ at $7.71 \mathrm{ppm}$ with $\mathrm{C}^{15}$ at $158.8 \mathrm{ppm}$, and $\mathrm{H}^{14}$ at 6.90 ppm with $\mathrm{C}^{12}$ at $143.4 \mathrm{ppm}$.

Figure $3 .{ }^{1} \mathrm{H}$ - and ${ }^{13} \mathrm{C}-\mathrm{NMR}$ of compound 15a.

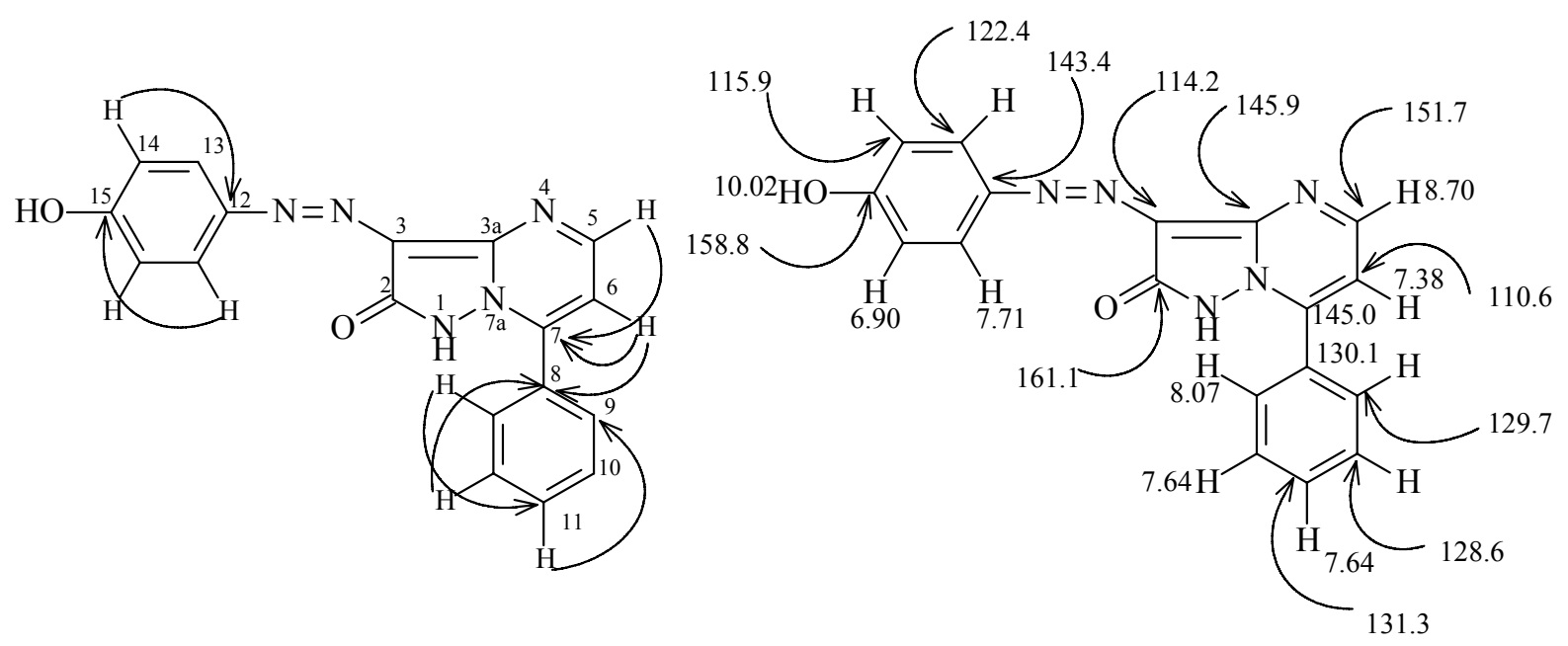

The possible formation of regioisomers 16 in reactions of 6 with enaminones 14a-d is ruled out based on ${ }^{1} \mathrm{H}_{-}{ }^{15} \mathrm{~N}$ HMBC experimental results. Conclusive data for the structure of 15a include chemical shifts for $\mathrm{N}^{7 \mathrm{a}}$ at $208.7 \mathrm{ppm}$ and $\mathrm{N}^{4}$ at $270.4 \mathrm{ppm}$. Cross peak correlations for coupling of the shielded proton $\mathrm{H}^{6}$ at $7.39 \mathrm{ppm}$ are observed with $\mathrm{N}^{7 \mathrm{a}}$ at $208.7 \mathrm{ppm}\left({ }^{3} J\right)\left(\mathrm{H}^{6}, \mathrm{~N}^{7 \mathrm{a}}\right)$ and $\mathrm{N}^{4}$ at $270.4 \mathrm{ppm}$ $\left({ }^{3} J\right)\left(\mathrm{H}^{6}, \mathrm{~N}^{4}\right)$. Coupling of the deshielded proton $\mathrm{H}^{5}$ at $7.70 \mathrm{ppm}$ with $\mathrm{N}^{4}$ at $270.4 \mathrm{ppm}\left({ }^{3} J\right)\left(\mathrm{H}^{5}, \mathrm{~N}^{4}\right)$ only is also observed. The results demonstrate that the phenyl moiety is located at $\mathrm{C}^{7}$ and not at $\mathrm{C}^{5}$. 


\subsection{Dyeing and Fastness Properties}

Arylazopyrazolopyrimidine derivatives 6, 7 and 15a-d were tested as dyes for polyester fibers using the high temperature dyeing method (HT) by employing microwave heating as an energy source. The physical and analytical data for the dyed fibers, given in Tables 1 and 2, reflect the efficiency of the microwave irradiation, leading to a large increase in dye uptake and dyeing rate along with a performance of dye leveling and color homogeneity.

\subsubsection{Color strength}

Data in Table 1 reveals that the color strengths $(\mathrm{K} / \mathrm{S})$ of dyed polyester fabrics are directly proportional to the amounts of the dyes applied (\% o.m.f.). The hues of the fabrics treated with the azo dyes were found to vary from yellowish-orange to dark orange, based on the substitution patterns. Differences in the color strength observed depend on the substitution patterns, 'auxochromes', present in the arylazopyrazolopyrimidine disperse dyes referred to as 'chromogens' $[14,23,24]$. Data in Table 1 clearly shows that the magnitude of color strength obtained using dye 15d is much larger than that for 15c.

Table 1. Color strength of dyed polyester using high temperature dyeing method.

\begin{tabular}{cccccc}
\hline \multirow{2}{*}{ Dye } & Color shade on & \multicolumn{4}{c}{ Color strength (K/S) \% Dye o.m.f. } \\
\cline { 3 - 6 } & polyester & $\mathbf{1}$ & $\mathbf{2}$ & $\mathbf{3}$ & $\mathbf{4}$ \\
\hline $\mathbf{6}$ & Yellowish-orange & 1.17 & 2.12 & 2.47 & 2.49 \\
$\mathbf{7}$ & Pale orange & 2.19 & 3.79 & 4.09 & 6.96 \\
$\mathbf{1 5 a}$ & Dark orange & 5.66 & 5.95 & 7.12 & 8.31 \\
$\mathbf{1 5 b}$ & Dark orange & 5.43 & 5.81 & 7.91 & 10.04 \\
15c & Orange & 4.40 & 4.64 & 4.85 & 6.01 \\
15d & Orange & 4.08 & 4.73 & 6.02 & 7.06 \\
\hline
\end{tabular}

\subsubsection{Wash fastness}

Fastness data, obtained by measuring color intensity changes in the dyed fabrics, are given in Table 2. It shows that wash fastness varies with the substitution patterns in the dyes, where an increase occurs when stronger electron-attracting groups are present on the aryl moieties. This might be attributed to the fact that these disperse dyes are mainly dispersed within the pores in the polyester fabrics and are held in their places by different forces including Van der Waal forces. Electron-attracting groups enable stronger Van der Waal forces and also hydrogen bonding with the dyed fabrics that increases their stability to washing.

\subsubsection{Light fastness}

The light fastness properties of substituted of fabrics treated with the disperse dyes were determined (Table 2). The low light fastness properties observed are most likely result the photochemical reactivity of the arylazopyrazolopyrimidine dyes. Indeed, the results of LCMS monitoring of the photolysate, obtained by irradiation of 3-(4-hydroxyphenylazo)-7-phenylpyrazolo[1,5-a]pyrimidin-2-one 
(14a), under $16 \mathrm{~W}$ low pressure mercurey arc-lamp $(254 \mathrm{~nm})$ in acetonitrile for $48 \mathrm{~h}$, supported this finding. Elnagdi et al. [25] observed that 3,4-diarylaminopyrazoles are reactive when treated under reflux with $\mathrm{AcOH}-\mathrm{H}_{2} \mathrm{SO}_{4}$ mixture.

Table 2. Fastness properties of azo disperse dyes on polyester fabrics, prepared by using high temperature dyeing method.

\begin{tabular}{|c|c|c|c|c|}
\hline \multirow{2}{*}{ Dye } & \multicolumn{3}{|c|}{ Wash fastness ${ }^{a, b}$} & \multirow{2}{*}{ Light fastness } \\
\hline & Alt & $\mathrm{SC}$ & SW & \\
\hline \multicolumn{5}{|c|}{ (1\% o.m.f. dyeing) } \\
\hline 6 & 5 & 5 & 5 & $2-3$ \\
\hline 7 & 5 & 5 & 5 & 2 \\
\hline $15 a$ & 5 & 5 & 5 & $2-3$ \\
\hline $15 b$ & 5 & 5 & 5 & 3 \\
\hline $15 c$ & 4 & 5 & 4 & $2-3$ \\
\hline 15d & 5 & 5 & 5 & 2 \\
\hline \multicolumn{5}{|c|}{ (2\% o.m.f. dyeing) } \\
\hline 6 & 5 & 5 & 5 & $2-3$ \\
\hline 7 & 5 & 5 & 5 & 2 \\
\hline $15 a$ & 5 & 5 & 5 & 2 \\
\hline $15 b$ & 5 & 5 & 5 & $2-3$ \\
\hline $15 c$ & 4 & 5 & 4 & $2-3$ \\
\hline 15d & 5 & 5 & 5 & 2 \\
\hline \multicolumn{5}{|c|}{ (3\% o.m.f. dyeing) } \\
\hline 6 & 5 & 5 & 5 & $2-3$ \\
\hline 7 & 5 & 5 & 5 & 2 \\
\hline $15 a$ & $4-5$ & 5 & $4-5$ & 2 \\
\hline $15 b$ & $4-5$ & 5 & $4-5$ & 2 \\
\hline $15 c$ & 4 & 5 & 4 & $2-3$ \\
\hline 15d & $4-5$ & $4-5$ & $4-5$ & 2 \\
\hline \multicolumn{5}{|c|}{ (4\% o.m.f. dyeing) } \\
\hline 6 & 5 & 5 & 5 & $2-3$ \\
\hline 7 & 5 & 5 & 5 & 2 \\
\hline $15 a$ & 5 & 5 & 5 & 2 \\
\hline $15 b$ & 5 & 5 & 5 & 2 \\
\hline $15 c$ & 4 & 5 & 4 & 2 \\
\hline 15d & $4-5$ & 5 & $4-5$ & 2 \\
\hline
\end{tabular}

\section{Experimental}

\subsection{General}

All melting points were recorded on a Gallenkamp apparatus and are uncorrected. IR spectra were recorded in $\mathrm{KBr}$ disks on a Perkin Elmer System 2000 FT-IR spectrophotometer. ${ }^{1} \mathrm{H}$ - and ${ }^{13} \mathrm{C}-\mathrm{NMR}$ spectra were recorded on a Bruker DPX $400 \mathrm{MHz}$ super-conducting NMR spectrometer. Mass spectra were measured on a VG Auto-spec-Q instrument (high resolution, high performance, tri-sector 
GC/MS/MS) and by LC-MS using an Agilent 1100 series LC/MSD with API-ES/APCI ionization mode. Microanalyses were performed on a LECO CH NS-932 Elemental Analyzer. The microwave oven used is a single mode cavity Explorer Microwave (CEM Corporation, Matthews, NC, USA) and irradiate in heavy-walled Pyrex tube (capacity $10 \mathrm{~mL}$ and $80 \mathrm{~mL}$ for dyeing). The color strengths (K/S) of the dyed polyester fabrics and the color fastness to light were evaluated at the Dyeing, Printing and Textile Auxiliaries Department, Textile Research Division, National Research Centre, Giza, Egypt.

\subsection{General Procedure for the Synthesis of azo Disperse Dyes}

Ethyl cyano(4-hydroxyphenylhydrazono)acetate (3). p-Aminophenol (10.9 g, 0.1 M) was dissolved in concentrated $\mathrm{HCl}(30 \mathrm{~m})$ and water cooled in ice $(20 \mathrm{~mL})$ and then $\mathrm{NaNO}_{2}(7 \mathrm{~g})$ in water $(50 \mathrm{~mL})$ was added in portions. A mixture of ethyl cyanoacetate $(10 \mathrm{~g}, 0.1 \mathrm{M})$, NaOAc $(20 \mathrm{~g})$, ethanol $(15 \mathrm{~mL})$ and water $(50 \mathrm{~mL})$ was prepared separately and cooled in ice. The diazonium salt solution was added slowly to the second solution, with ice cooling. The cooled mixture was stirred for $0.5 \mathrm{~h}$ and filtered to give brown crystals, which were crystallized from alcohol/water to yield $2.0 \mathrm{~g}(86 \%)$ of 3, m.p. 273-274 ${ }^{\circ} \mathrm{C}$. MS: $m / z=331\left(\mathrm{M}^{+}, 100 \%\right), 238$ (50\%), 182 (20\%). IR: 3432, 3066, 3003, 1623, 1591, 1531, 1461, 1232, $829 \mathrm{~cm}^{-1} .{ }^{1} \mathrm{H}-\mathrm{NMR}\left(\mathrm{DMSO}_{\mathrm{d}}\right) 13.02$ (s, 1H, NH, syn), 12.16 (s, 1H, NH, anti), $9.68(\mathrm{~s}, 1 \mathrm{H}, \mathrm{OH}$, syn), $9.57(\mathrm{~s}, 1 \mathrm{H}, \mathrm{OH}$, anti), $7.36(\mathrm{~d}, 2 \mathrm{H}, J=7.4 \mathrm{~Hz}$, syn), $7.31(\mathrm{~d}, 2 \mathrm{H}$, $J=8.0 \mathrm{~Hz}$, anti), $6.81(\mathrm{~d}, 4 \mathrm{H}, J=8.0 \mathrm{~Hz}$, syn+anti), 4.30 (q, 2H, syn), 4.24 (q, 2H, anti), 1.32 (t, 3H, syn), 1.28 ppm (t, 3H, anti). ${ }^{13} \mathrm{C}-\mathrm{NMR}$ (DMSO-d 6 ) 161.4, 161.3, 155.9, 155.3, 134.2, 133.5, 118.0, $117.9,116.4,116.0,115.9,112.0,101.9,101.4,61.7,61.2,14.2,14.0$ ppm. HRMS = 233.0794, requires $\mathrm{C}_{11} \mathrm{H}_{11} \mathrm{~N}_{3} \mathrm{O}_{3} 233.0794$.

5-Amino-4-[(4-hydroxyphenyl)-hydrazono]-2,4-dihydropyrazol-3-one (6). A mixture of 3 (2.33 g, $10 \mathrm{mmol})$, hydrazine hydrate $(2.5 \mathrm{~mL})$ in ethanol $(20 \mathrm{~mol})$ was stirred at reflux for $3-4 \mathrm{~h}$. The solvent was removed under vacuum and the formed solid was collected and crystallized from ethanol/water to give 6. Red brown crystals from alcohol, yield 2.6 g (73\%), m.p. $263{ }^{\circ} \mathrm{C}$. MS: $m / z=219\left(\mathrm{M}^{+}, 100 \%\right)$, 126 (10\%), 108 (60\%). IR: 3472, 3361, 3283, 3165, 3130, 1678, 1626, 1268, $820 \mathrm{~cm}^{-1}$. ${ }^{1} \mathrm{H}-\mathrm{NMR}$ $\left(\mathrm{DMSO}_{6} \mathrm{~d}_{6} 12.90\right.$ (br, 1H, NH), 10.45 (s, 1H, NH), 9.50 (br, 1H, OH), 7.37 (d, 2H, J=8.0 Hz) 6.78 $(\mathrm{d}, 2 \mathrm{H}, J=8.0 \mathrm{~Hz}) 5.71 \mathrm{ppm}\left(\mathrm{br}, 2 \mathrm{H}, \mathrm{NH}_{2}\right) ;{ }^{13} \mathrm{C}-\mathrm{NMR}\left(\mathrm{DMSO}-\mathrm{d}_{6}\right)$ 160.7, 158.8, 151.6, 144.9, 143.4, $131.3,130.0,129.6,128.5,122.4,115.9,114.1,110.6,115.7 \mathrm{ppm}$.

General procedure for the synthesis of pyrazolo[1,5-a]pyrimidines 7, 10 and 15a-d

A mixture containing $6(0.22 \mathrm{~g}, 10 \mathrm{mmol})$, and acetylacetone, 2-piperidinylacrylonitrile or enaminones 5a-d $(1 \mathrm{mmol})$ in acetic acid $(5 \mathrm{mmol})$ was irradiated in a microwave oven at $140{ }^{\circ} \mathrm{C}$ for $2 \mathrm{~min}$. The mixture was then poured into ice water $(50 \mathrm{~mL})$. The formed was collected and crystallized from the appropriate solvent (see below).

3-(4-Hydroxyphenylazo)-5,7-dimethylpyrazolo[1,5-a]pyrimidin-2-one (7). Red crystals from DMF, yield 2.79 g (73\%), m.p. $277-278{ }^{\circ} \mathrm{C}$. MS: $\mathrm{m} / \mathrm{z}=283\left(\mathrm{M}^{+}, 100 \%\right), 190$ (90\%), 162 (30\%). IR: 3458, $3113,3013,1620,1534,1423,1250,1139,840 \mathrm{~cm}^{-1} .{ }^{1} \mathrm{H}-\mathrm{NMR}$ (DMSO-d $) 9.94$ (s, 1H, OH), 7.63 (dd, $\left.2 \mathrm{H}, \mathrm{H}^{13} J=7.4,1.8 \mathrm{~Hz}\right), 7.06\left(\mathrm{~s}, 1 \mathrm{H}, \mathrm{H}^{6}\right), 6.88\left(\mathrm{dd}, 2 \mathrm{H}, \mathrm{H}^{14}, J=7.4,1.8 \mathrm{~Hz}\right), 3.43(\mathrm{br}, 1 \mathrm{H}, \mathrm{NH}), 2.58$ 
(s, 3H), $2.51 \mathrm{ppm}(\mathrm{s}, 3 \mathrm{H}) .{ }^{13} \mathrm{C}-\mathrm{NMR}$ (DMSO-d $)$ 161.5, 161.2, 158.4, 146.4, 144.4, 141.5, 121.6, 116.0, 114.8, 111.9, 24.0, 16.5 ppm. Anal. Calcd. for $\mathrm{C}_{14} \mathrm{H}_{13} \mathrm{~N}_{5} \mathrm{O}_{2}$ (283.3): C 59.36; H 4.63, N 24.72. Found: C 59.30; H 4.57; N 24.71.

7-Amino-3-(4-hydroxyphenylazo)pyrazolo[1,5-a]pyrimidin-2-one (10). Red crystals from DMF, yield 2.79 g (73\%), m.p. $273{ }^{\circ} \mathrm{C}$. MS: $m / z=270\left(\mathrm{M}^{+}, 75 \%\right), 177$ (35\%), 150 (100\%). IR: 3353, 3146, 2926, 1649, 1620, 1543, 1444, 1239, 1176, $823 \mathrm{~cm}^{-1} .{ }^{1} \mathrm{H}-\mathrm{NMR}$ (DMSO-d $) 9.66(\mathrm{~s}, 1 \mathrm{H}, \mathrm{OH}), 8.10(\mathrm{~d}, 1 \mathrm{H}$, $\left.\mathrm{H}^{5}, J=6.0 \mathrm{~Hz}\right), 7.91\left(\mathrm{br}, 2 \mathrm{H}, \mathrm{NH}_{2}\right), 7.50(\mathrm{~d}, 2 \mathrm{H}, J=8.0 \mathrm{~Hz}), 6.86(\mathrm{~d}, 2 \mathrm{H}, J=8.0 \mathrm{~Hz}), 6.47 \mathrm{ppm}$ $\left(\mathrm{d}, 1 \mathrm{H}, \mathrm{H}^{6}, J=6.0 \mathrm{~Hz}\right) .{ }^{13} \mathrm{C}-\mathrm{NMR}\left(\mathrm{DMSO}_{-}\right)_{6} \delta 163.6,156.9,150.0,147.1,164.0,137.9,119.6$, 118.1., 116.0, 97.1 ppm. Anal. Calcd. for $\mathrm{C}_{12} \mathrm{H}_{9} \mathrm{~N}_{6} \mathrm{O}_{2}$ (269.2): C 53.53; H 3.37, N 31.21. Found: C 53.47; H 3.27; N 31.05 .

3-(4-Hydroxyphenylazo)-7-phenylpyrazolo[1,5-a]pyrimidin-2-one (15a). Red crystals from DMF, yield 2.6 g (78\%), m.p. $273-274{ }^{\circ} \mathrm{C}$. MS: m/z = $331(\mathrm{M}+, 100 \%), 238$ (50\%), 182 (20\%). IR: 3432, 3066, 3003, 1623, 1591, 1531, 1461, 1232, $829 \mathrm{~cm}^{-1} .{ }^{1} \mathrm{H}-\mathrm{NMR}$ (DMSO-d $) 10.02$ (s, 1H, OH), 8.70 (d, $\left.1 \mathrm{H}, \mathrm{H}^{5}, J=4.2 \mathrm{~Hz}\right), 8.07\left(\mathrm{dd}, 2 \mathrm{H}, \mathrm{H}^{9}, J=7.2,1.8 \mathrm{~Hz}\right), 7.71\left(\mathrm{dd}, 2 \mathrm{H}, \mathrm{H}^{13}, J=7.2,1.8 \mathrm{~Hz}\right), 7.64(\mathrm{~m}$, $\left.3 \mathrm{H}, \mathrm{H}^{10}, \mathrm{H}^{11}\right), 7.38\left(\mathrm{~d}, 1 \mathrm{H}, \mathrm{H}^{6}, J=4.2 \mathrm{~Hz}\right), 6.90\left(\mathrm{dd}, 2 \mathrm{H}, \mathrm{H}^{14}, J=7.2,1.8 \mathrm{~Hz}\right), 3.36 \mathrm{ppm}(\mathrm{br}, 1 \mathrm{H}, \mathrm{NH})$. ${ }^{13} \mathrm{C}-\mathrm{NMR}\left(\mathrm{DMSO}_{\mathrm{d}}\right.$ ) 161.1, 158.8, 151.7, 145.0, 145.9, 143.4, 131.3, 130.1, 129.7, 128.6, 122.4, 115.9, 114.2, 110.6 ppm. Anal. Calcd. for $\mathrm{C}_{18} \mathrm{H}_{13} \mathrm{~N}_{5} \mathrm{O}_{2}$ (331.3): C 65.25; H 3.95; N 21.14. Found: C $64.93 ;$ H $3.92 ; \mathrm{N} 21.03$.

7-(4-Chlorophenyl)-3-(4-hydroxyphenylazo)pyrazolo[1,5-a]pyrimidin-2-one (15b). Red crystals from DMF, yield 2.7 g (84\%), m.p. $285-286{ }^{\circ} \mathrm{C}$. MS: $m / z=365\left(\mathrm{M}^{+}, 100 \%\right), 272(60 \%), 149$ (25\%). IR: 3430, 3227, 3095, 1633, 1596, 1514, 1483, 1445, 1253, $821 \mathrm{~cm}^{-1} .{ }^{1} \mathrm{H}-\mathrm{NMR}$ (DMSO-d $\left.)_{6}\right) 10.02$ (s, 1H, $\mathrm{OH}), 8.71(\mathrm{~d}, 1 \mathrm{H}, J=4.8 \mathrm{~Hz}), 8.13(\mathrm{dd}, 2 \mathrm{H}, J=7.2,1.8 \mathrm{~Hz}), 7.71(\mathrm{~m}, 4 \mathrm{H}), 7.42(\mathrm{~d}, 1 \mathrm{H}$, $J=4.8 \mathrm{~Hz}$ ), 6.89 (dd, 2H, $J=7.2,1.8 \mathrm{~Hz}), 3.38 \mathrm{ppm}(\mathrm{br}, 1 \mathrm{H}, \mathrm{NH}) .{ }^{13} \mathrm{C}-\mathrm{NMR}$ (DMSO-d 6 ) 161.0, 158.8, 151.6, 144.9, 144.7, 143.3, 136.1, 131.5, 128.8, 128.6, 122.4, 115.9, 114.2, 110 ppm. Anal. Calcd. for $\mathrm{C}_{18} \mathrm{H}_{12} \mathrm{ClN}_{5} \mathrm{O}_{2}$ (365.8): C 59.11; H 3.31, N 19.15. Found: C 58.78; H 3.32; N 18.90.

7-Furan-2-yl-3-(4-hydroxyphenylazo)pyrazolo[1,5-a]pyrimidin-2-one (15c). Red crystals from DMF, yield 2.7 g (84\%), m.p. $291-292{ }^{\circ} \mathrm{C} . \mathrm{MS}: \mathrm{m} / \mathrm{z}=321\left(\mathrm{M}^{+}, 100 \%\right), 228$ (45\%), 172 (15\%). IR: 3429, $3109,3035,1626,1594,1536,1462,1238,1132,828 \mathrm{~cm}^{-1} .{ }^{1} \mathrm{H}$ NMR (DMSO-d 6$) 10.01$ (s, 1H, OH), $8.67(\mathrm{~d}, 1 \mathrm{H}, J=4.8 \mathrm{~Hz}), 8.23(\mathrm{~d}, 1 \mathrm{H}, J=3.6 \mathrm{~Hz}), 8.15(\mathrm{~d}, 1 \mathrm{H}, J=3.6 \mathrm{~Hz}), 7.69$ (d, 2H, $J=8.4 \mathrm{~Hz})$, $7.62(\mathrm{~d}, 1 \mathrm{H}, J=4.8 \mathrm{~Hz}), 6.95(\mathrm{~m}, 1 \mathrm{H}), 6.89(\mathrm{~d}, 2 \mathrm{H}, J=8.4 \mathrm{~Hz}), 3.37 \mathrm{ppm}(\mathrm{br}, 1 \mathrm{H}, \mathrm{NH}) .{ }^{13} \mathrm{C}-\mathrm{NMR}$ (DMSO-d $\left.{ }_{6}\right)$ 162.1, 158.6, 150.5, 147.9, 145.0, 142.6, 141.9, 134.6, 121.9, 120.9, 115.9, 114.7, 113.6, 105.8 ppm. Anal. Calcd. for $\mathrm{C}_{16} \mathrm{H}_{11} \mathrm{~N}_{5} \mathrm{O}_{3}$ (321.3): C 59.81; H 3.45, N 21.80. Found: C 59.78; H 3.34; N 21.81 .

3-(4-Hydroxyphenylazo)-7-thiophen-2-yl-pyrazolo[1,5-a]pyrimidin-2-one (15d). Red crystals from DMF, yield 2.6 g (77\%), m.p. $284-285{ }^{\circ} \mathrm{C} . \mathrm{MS}: \mathrm{m} / \mathrm{z}=337\left(\mathrm{M}^{+}, 100 \%\right), 244$ (50\%), 188 (20\%). IR: 3429, 3104, 3035, 1623, 1592, 1535, 1462, 1238, 1160, $826 \mathrm{~cm}^{-1} .{ }^{1} \mathrm{H}-\mathrm{NMR}\left(\mathrm{DMSO}-\mathrm{d}_{6}\right) 9.99$ (s, 1H, $\mathrm{OH}), 8.62(\mathrm{~d}, 1 \mathrm{H}, J=4.8 \mathrm{~Hz}), 8.55(\mathrm{~d}, 1 \mathrm{H}, J=3.6 \mathrm{~Hz}), 8.19(\mathrm{~d}, 1 \mathrm{H}, J=4.8 \mathrm{~Hz}), 7.98(\mathrm{~d}, 1 \mathrm{H}$, $J=4.2 \mathrm{~Hz}), 7.67(\mathrm{~d}, 2 \mathrm{H}, J=8.4 \mathrm{~Hz}), 7.41(\mathrm{t}, 1 \mathrm{H}, J=4.2 \mathrm{~Hz}), 6.89(\mathrm{~d}, 2 \mathrm{H}, J=8.4 \mathrm{~Hz}), 3.38 \mathrm{ppm}(\mathrm{br}$, 
1H, NH). ${ }^{13} \mathrm{C}-\mathrm{NMR}$ (DMSO-d D 162.6, 158.2, 150.1, 145.5, 140.4, 139.1, 136.2, 133.1, 129.4, 127.8, 121.3, 116.0, 115.7, 108.0 ppm. Anal. Calcd. for $\mathrm{C}_{16} \mathrm{H}_{11} \mathrm{~N}_{5} \mathrm{O}_{2} \mathrm{~S}$ (337.4): C 56.96; H 3.29, N 20.76 ; S 9.50. Found: C 56.88; H 3.30; N 20.71 ; S 9.46.

\subsection{High Temperature Dyeing Method (HT)}

\subsubsection{Materials}

Scoured and bleached polyester 100\% (150 $130 \mathrm{~g} / \mathrm{m}^{2}, 70 / 2$ denier) was obtained from El-Shourbagy Co., Egypt. The fabric was treated before dyeing with a solution containing non-ionic detergent (Hostapal CV, Clariant-Egypt, $5 \mathrm{~g} / \mathrm{L}$ ) and sodium carbonate $(2 \mathrm{~g} / \mathrm{L})$ in a ratio of $50: 1$ at $60{ }^{\circ} \mathrm{C}$ for $30 \mathrm{~min}$, then thoroughly washed with water and air dried at room temperature.

\subsubsection{Dyeing}

Dyeing of polyester fabrics was carried out at $130{ }^{\circ} \mathrm{C}$ for $60 \mathrm{~min}$, under pressure in a microwave oven in a 20:1 liquor ratio and $\mathrm{pH} 5.5$ in the presence of a 1:1 ratio of the dispersing agent sodium lignin sulphonate and the with a $1-4 \%$ shade. After dyeing, the fabrics were thoroughly washed and then subjected to a surface reduction cleaning $[(5 \mathrm{~g} \mathrm{NaOH}+6 \mathrm{~g}$ sodium hydrosulphite $) / \mathrm{L}]$. The samples were heated in this solution for $10 \mathrm{~min}$. at $60{ }^{\circ} \mathrm{C}$ and then thoroughly washed and air-dried.

\subsection{Color Measurements and Analyses}

\subsubsection{Color measurements of the dyed fabrics}

The color yields of the dyed samples were determined by using the light reflectance technique performed on a Perkin-Elmer (Lambda 3B) UV/VIS Spectrophotometer. The color strengths, expressed as $\mathrm{K} / \mathrm{S}$ values, were determined by applying the Kubelka-Mink equation as follows:

$$
\mathrm{K} / \mathrm{S}=\left[(1-\mathrm{R})^{2} / 2 \mathrm{R}\right]-\left[\left(1-\mathrm{R}_{\mathrm{o}}\right)^{2} / 2 \mathrm{R}_{\mathrm{o}}\right]
$$

where $R=$ decimal fraction of the reflectance of the dyed fabric; $R_{O}=$ decimal fraction of the reflectance of the undyed fabric; $K=$ absorption coefficient; $S=$ scattering coefficient.

\subsubsection{Fastness testing}

After washing using $2 \mathrm{~g} / \mathrm{L}$ of the non-ionic detergent Hostapal $\mathrm{CV}$ at $80{ }^{\circ} \mathrm{C}$ for $15 \mathrm{~min}$, the dyed fabrics were tested, employing ISO standard methods [26]. Wash fastness tests were carried out in accordance with ISO 105-C04 (1989), in which $5 \mathrm{~g} / \mathrm{L}$ soap and $2 \mathrm{~g} / \mathrm{L}$ soda ash solution were used at $95{ }^{\circ} \mathrm{C}$ for $30 \mathrm{~min}$ in the presence of 10 steel balls (liquor ratio 50:1) and color fastness to light (carbon arc), ISO 105-B02 (1988). 


\section{Conclusions}

In summary, a series of novel monoazo disperse pyrazolopyrimidine dyes were synthesized via a sequence involving initial coupling of ethyl cyanoacetate with 4-hydroxybenzenediazonium chlorides. Subsequent treatment with hydrazine hydrate gave the corresponding pyrazolohydrazone that was then treated with either 2,5-pentandione or arylenaminoketones to give the target pyrazolo[1,5-a]pyrimidine dyes. The dyes produced in this manner were then applied to polyester fibers by using HT dyeing conditions and microwave heating. The dyed fabrics, which displayed yellow to yellow brown hues on polyester fibers, have low fastness levels to light and excellent wash fastness.

\section{Acknowledgments}

The support of the Public Authority for Applied Education and Training, for finance through project (HS-08-02) and the facilities of AnaLab (SAF) at Kuwait University are gratefully acknowledged.

\section{References}

1. Singh, S.P.; Kumar, D. Reinvestigation of the Reported Synthesis of Naphtho[2',1',4,5]thiazolo[2,3-c][1,2,4]triazepines. Heterocycles 1990, 31, 855-860.

2. Abdel-Ghany, Y.S. Novel 1,3,4-trisubstituted pyrazole derivatives: design, synthesis and biological evaluation as anti -inflammatory/ antimicrobial agents. Alex. J. Pharm. Sci. 2008, 22, 31-39.

3. Kaymakcioglu, B.K.; Rollas, S.; Korcegez, E.; Aricioglu, F. Synthesis and biological evaluation of new N-substituted-N'-(3,5-di/1,3,5-trimethylpyrazole-4-yl)thiourea/urea derivatives Eur. J. Pharm. Sci. 2005, 26, 97-103.

4. Langer, P.; Wuckelt, J.; Doring, M.; Schreiner, P.R.; Gorls, H. Regioselective anionic [3+2] cyclizations of isoxazole, pyrazole and 1,2,4-triazole dinucleophiles: Efficient synthesis of 2,4dihydroimidazo[4,5-b]quinoxalines, 3H-imidazo[1,2-b]pyrazoles and 5H-imidazo[2,1-c][1,2,4]triazoles. Eur. J. Org. Chem. 2001, 12, 2257-2263.

5. Ho, Y.W.; Wang, I.J. Heterocyclic Monoazo dyes derived from 3-cyano-2(1H)-pyridinethione. Part 2: 2-[[4-(Arylazo)-3,5-disubstituted-pyrazol-1-yl]carbonyl]-thieno[2,3-b]pyridine derivatives Dye. Pigment. 1995, 29, 295-304.

6. Jain, R.; Shukla, A. Synthesis of some new derivatives of pyrazolin - 5 - ones. J. Ind. Chem. Soc. 1990, 67, 575-576.

7. Henning, G. Pyrazolone azo dyes. CODEN: GWXXBX DE 2616981 A1 19771027. 27 October 1977.

8. Schmidt, P.; Druey, J. Chemotherapeutic studies in the heterocyclic series. XIV. Pyrazolo[3,4d]pyrimidines. Helv. Chim. Acta 1956, 39, 986-991.

9. Ho, Y.W. Synthesis of some new azo pyrazolo[1,5-a]pyrimidine-thieno[2,3-b]pyridine derivatives and their application as disperse dyes. Dye. Pigment. 2005, 64, 223-230.

10. Tsai, P.C.; Wang, I.J. A facile synthesis of some new pyrazolo[1,5-a]pyrimidine heterocyclic disazo dyes and an evaluation of their solvatochromic behaviour, Dye. Pigment. 2007, 74, 578-584. 
11. Tsai, P.C.; Wang, I.J. Synthesis and solvatochromic properties of 3,6-bis-hetarylazo dyes derived from pyrazolo[1,5-a]pyrimidine. Dye. Pigment. 2008, 76, 575-581.

12. Tsai, P.C.; Wang, I.J. Synthesis and solvatochromic properties of some disazo dyes derived from pyrazolo[1,5-a]pyrimidine derivatives. Dye. Pigment. 2005, 64, 259-264.

13. Karcı, F.; Demirçalı, A. Synthesis of disazo pyrazolo[1,5-a]pyrimidines. Dye. Pigment. 2007, 74, 288-297.

14. El-Kholy, Y.M.; Abdel-Hafiz, S.A.; Ahmed, S.H. Synthesis and dyeing properties of novel disperse dyes. Part 2: Pyrazole disperse dye derivatives. J. Soc. Dyers Colour. 1998, 114, 45-48.

15. Haggag, K.; Hanna, H.L.; Youssef, B.M.; El-Shimy, N.S. Dyeing Polyester With Microwave Heating Using Disperse Dyestuffs. Am. Dyestuff Rep. 1995, 84, 22-35.

16. El-Apasery, M.A. Solvent-Free One-Pot Synthesis of Some Azo Disperse Dyes under Microwave Irradiation: Dyeing of Polyester Fabrics. J. Appl. Poly. Sci. 2008, 109, 695-699.

17. El-Apasery, M.A. Synthesis of some azo disperse dyes by the use of focused microwave heating. Pol. J. Appl. Chem. 2006, 50, 75-81.

18. Brecknell, D.J.; Carman, R.M.; Deeth, H.C.; Kibby, J.J. Some simple cyanoformaldehyde phenylhydrazones. Aust. J. Chem. 1969, 22, 1915-22.

19. El-Dusouqui, O.M.E.; Abdelkhalik, M.M.; Al-Awadi, N.A.; Dib, H.H.; George, B.J.; Elnagdi, M.H. Chemistry of 2-arylhydrazonals: utility of substituted 2-arylhydrazono-3oxoalkanals as precursors for 3-oxoalkanonitriles, 3-aminoisoxazole and 1,2,3- and 1,2,4triazoles. J. Chem. Res. 2006, 5, 295-302.

20. Elnagdi, M.H.; Abd Allah, S.O. Reaction with the arylhydrazones of some $\alpha$-cyano ketones. J. Prakt. Chem. 1973, 315, 1009-1016.

21. Elgemeie, G.E.H.; Fathy, N.M.; Faddah, L.M.; Ebeid, M.Y.; Elsaid, M.K. Reactions with 3,5diaminopyrazoles: New routes to pyrazolo[1,5-a]pyrimidines. Arch. Pharm. 1991, 324, 149-152.

22. Sharaf, M.A.F.; Abd El-Aal, F.A.; Elgemeie, G.E.H.; El-Damaty, A.A. Reactions with diethyl acetonedicarboxylate: Novel synthesis of pyrazolo[3,4-d]pyridazine derivatives. Arch. Pharm. 1991, 324, 585-587.

23. Peters, R.H.; Sumner, H.H. The affinities of vat dyes in relation to their constitutions. J. Soc. Dyers Colour. 1955, 71, 130-138.

24. Andrews, B.A.K.; Blanchard, E.J.; Reinhardt, R.M. Fabric whiteness retention in durable press finishing with citric acid. Text. Chem. Color. 1993, 25, 52-54.

25. Elnagdi, M.H.; Kandeel, E.M.; Zayed, E.M.; Kandil, Z.E. Pyrimidine derivatives and related compounds. VI. A novel synthesis of 3,5-diacetamidopyrazole and of 2-aminopyrazolo[1,5a]pyrimidines. J. Heterocycl. Chem. 1977, 14, 155-157.

26. Chrysler. L.P. Methods of Test for Color Fastness of Textiles and Leather, 7th ed.; Bradford: London, UK, 1990; pp. 89-94.

Sample Availability: Samples of the compounds 6, 7, 10 and 15a-d are available from the authors

(C) 2011 by the authors; licensee MDPI, Basel, Switzerland. This article is an open access article distributed under the terms and conditions of the Creative Commons Attribution license (http://creativecommons.org/licenses/by/3.0/). 